\title{
Quality Control Studies on Conventional Carbamazepine Tablets Available in the Indian Drug Market
}

Kajal Ghosal", Subhash Ranu, Moktasd Billah, Sudhamoy Mondal, and Masudul Hoque

Dr. B. C. Roy College of Pharmacy and AHS, Bidhannagar, Durgapur - 713206, West Bengal, India

\begin{abstract}
Carbamazepine (CBZ) is widely used as an antiepileptic drug, primarily for the treatment of partial and tonic-clonic seizures. The drug is absorbed slowly and variably after oral administration due to its limited water solubility. In clinics, single daily dosing of conventional dosage forms of CBZ is insufficient; effective CBZ levels are provided by multiple-dose administration. Multiplicity of dosage causes inconsistent plasma CBZ levels leading to side effects because of its narrow therapeutic and toxicity levels. The main aim of this paper is to compare four commercial brands of carbamazepine tablets that are available in the Indian drug market. Different quality control parameters such as weight variation, diameter and thickness, content uniformity, friability, and dissolution profiles were tested .Difference $\left(f_{1}\right)$ and similarity $\left(f_{2}\right)$ data analyses were carried out to demonstrate the differences between these commercial brands. The results of weight variations, diameter and thickness, content uniformity, and friability are comparable to the acceptable standard limits described by pharmacopeias such as USP. Though differences for release profiles exist, all the commercial brands released $75 \%$ of drug labeled amount within $1 \mathrm{hr}$ according to USP, so they can satisfy patient need.
\end{abstract}

\section{INTRODUCTION}

$\mathrm{P}$ roduct quality must be maintained to achieve the desired efficacy and at the same time prevent unwanted and hazardous effects. It is essential to check the performance of the production process and prevent the marketing of product that does not fulfill this goal. Carbamazepine was initially approved in 1974 for use as an antiseizure agent. It has been employed since the 1960s for the treatment of trigeminal neuralgia and is now considered a primary drug for the treatment of partial and tonic-clonic seizures (1). A single daily dose of CBZ is insufficient; two doses per day are appropriate in most cases, but some patients may benefit from more frequent dosing to avoid side effects (2). The drug is characterized by its limited aqueous solubility, which results in slow and variable absorption after oral administration.

In clinical studies, suspensions, conventional tablets, and XR (extended-release) tablets delivered equivalent amounts of drug to the systemic circulation (3). However, the suspension was absorbed somewhat more rapidly and XR tablets slightly slower than the conventional tablet. Bioavailability of the XR tablet was $89 \%$ compared with the suspension. In a twice-daily (b.i.d.) dosage regimen, the suspension provided higher peak levels and lower trough levels than those obtained from the conventional tablet for the same dosage regimen. Administered in a three-times-daily dosage regimen, $C B Z$ suspension afforded steady-state plasma levels comparable to CBZ tablets given b.i.d. when administered at the same total daily dose.

${ }^{*}$ Corresponding author.
In this study, we worked on the quality control of conventional CBZ tablets that are available in the Indian drug market. Quality control tests of weight variation, diameter and thickness, content uniformity, hardness, friability, and dissolution were performed to determine if they meet the specific criteria for quality parameters.

\section{MATERIALS AND METHODS \\ Materials}

Carbamazepine was kindly donated from Sun Pharma, Dadra, India. In our study, four commercial Indian brands of conventional tablets containing $200 \mathrm{mg}$ of CBZ were purchased from a pharmacy retail shop and coded as CBZ A (Lot:001), CBZ B (Lot:002), CBZ C (Lot:003), and CBZ D (Lot:004). The Indian manufacturers were Torrent, La Pharma, Novartis India, and Nicholas Piramal India Limited. All other chemicals used in the study were of analytical grade.

\section{Analytical Method}

Accurately weighed carbamazepine was dissolved in distilled water containing $1 \%$ sodium lauryl sulfate in a I00-mL volumetric flask. From the stock solution, different dilutions were prepared to generate a calibration curve by measuring absorbance using a UV spectrophotometer (Shimadzu 1202 UV spectrophotometer) at $287 \mathrm{~nm}$. The concentration of carbamazepine was calculated using the linear regression equation of the calibration curve. Mean standard error (accuracy) and RSD (precision) were 0.3\% and $0.5 \%$, respectively $(n=6)$.

\section{Weight Variation}

Ten tablets of each brand were chosen randomly and weighed with an electronic balance (Citizen Electronic Precision Balance) (4). 
Table 1. Results Obtained from Weight Variation Measurement

\begin{tabular}{lcccc}
\hline CBZ Tablet & $\begin{array}{c}\text { Minimum } \\
\text { Weight (g) }\end{array}$ & $\begin{array}{c}\text { Maximum } \\
\text { Weight (g) }\end{array}$ & $\begin{array}{c}\text { Average } \\
\text { Weight (g) }\end{array}$ & $\begin{array}{c}\text { Standard } \\
\text { Deviation (SD) } \\
\text { CBZ A }\end{array}$ \\
\hline Deviation (RSD)
\end{tabular}

\section{Measurement of Diameter and Thickness}

The diameter and thickness of CBZ tablets $(n=10)$ from each brand were measured with dial calipers (5).

\section{Hardness Test}

Based on the USP method (6), 10 tablets for each brand were taken separately, and the degree of hardness of each type was tested with a hardness tester (Monsanto). Each tablet was placed on the lower plunger of the instrument such that the tablet just touched the upper plunger, and a zero reading was taken. The upper plunger was then forced until the tablet fractured. A pointer moving along the scale provided the hardness of the tablet.

\section{Friability Test}

Ten tablets from each commercial brand were weighed separately, and each set of tablets was put into the friabilator (Roche Friabilator). Then the tablets were rotated at $25 \mathrm{rpm}$, and the procedure was operated for 4 min. After this, the tablets were removed and weighed again. The friability percentage was calculated for each batch.

\section{Content Uniformity Test}

The amount of CBZ in each tablet brand was determined according to USP (6). A standard solution was prepared by dissolving pure $C B Z$ in methanol, and sample solutions were prepared by dissolving CBZ tablets $(n=20)$ from each batch in methanol. The absorbance of each prepared solution was determined at $287 \mathrm{~nm}$ by UV spectrophotometer. The CBZ amount in each tablet was calculated using the equation for the calibration curve that was prepared for the content uniformity test.

\section{Dissolution Studies}

The dissolution rate studies on conventional CBZ tablets were carried out according to the USP paddle method at a stirring rate of $75 \mathrm{rpm}$. The dissolution medium was 900 $\mathrm{mL}$ of distilled water containing $1 \%$ sodium lauryl sulfate at $37 \pm 0.5^{\circ} \mathrm{C}$. The samples were withdrawn at 10 -min intervals up to one hour and assayed spectrophotometrically at $287 \mathrm{~nm}$. The percentage of cumulative CBZ released was calculated using the linear regression equation of the calibration curve.

\section{Comparison of Dissolution Profiles}

A mathematical comparison was performed by applying $f_{1}$ and $f_{2}$. Values of $f_{1}$ between 0 and 15 and values of $f_{2}$ between 50 and 100 are used to define equivalence of two dissolution profiles (7):

$$
\begin{gathered}
f_{1}=\left\{\left[\sum_{t=1}^{n}\left|R_{t}-T_{t}\right|\right] /\left[\sum_{t=1}^{n} R_{t}\right]\right\} \times 100 \\
f_{2}=50 \cdot \log \left\{\left[1+\frac{1}{n} \sum_{t=1}^{n}\left(R_{t}-T_{t}\right)^{2}\right]^{-0.5} \times 100\right\}
\end{gathered}
$$

where $n$ is the number of dissolution sample times, and $R_{t}$ and $T_{t}$ are the mean percent dissolved at each time point $t$ for the reference and test dissolution profiles, respectively.

\section{RESULTS AND DISCUSSION}

A quality control study is very important to evaluate tablet properties. Different quality control parameters (e.g. weight variation, diameter, thickness, content uniformity, friability, and dissolution tests) were performed to determine the differences among various conventional carbamazepine tablets that are available in the Indian drug market.

\section{Weight Variation}

According to the USP (6), the weight of each individual tablet should be within the allowed percentage limit (7.5\%) of the average weight (if the average weight is between 130 and $324 \mathrm{mg}$ ). The results are given in Table 1. Weights of the tablets from different commercial brands were within the acceptance limits.

\section{Measurement of Diameter and Thickness}

The size and shape of the tablet depend on the diameter and thickness of the tablet. Variation among tablets can be determined by measuring the thickness and diameter of the tablets. From Table 2 it is observed that the standard deviations for diameter and thickness are small, so the size and shape for each commercial brand are consistent.

\section{Hardness Test}

For a satisfactory tablet, hardness should not be so high that disintegration and dissolution are delayed. Conversely, hardness should not be so low that tablets are soft and 
Table 2. Results of Quality Control Tests

\begin{tabular}{|c|c|c|c|c|c|}
\hline CBZ Tablet & Hardness (mean \pm SD) & Diameter $(\mathrm{cm})$ & Thickness (cm) & Friability (\%) & Content Uniformity (\%) \\
\hline CBZ A & $8.3 \pm 1.321$ & $0.876 \pm 0.001$ & $0.323 \pm 0.004$ & 0.017 & 95 \\
\hline CBZ B & $4.74 \pm 1.11$ & $0.956 \pm 0.001$ & $0.373 \pm 0.001$ & 0.014 & 98 \\
\hline CBZ C & $7.87 \pm 1.47$ & $0.906 \pm 0.002$ & $0.366 \pm 0.002$ & 0.002 & 97 \\
\hline CBZ D & $4.8 \pm 0.876$ & $0.605 \pm 0.001$ & $0.390 \pm 0.004$ & 0.004 & 102 \\
\hline
\end{tabular}

friable. For a satisfactory tablet, hardness should be between 4 and $8 \mathrm{~kg}$ (8). The results in Table 2 show that hardness was satisfactory for all commercial carbamazepine brands.

\section{Friability Test}

The friability value should be lower than $0.5-1 \%$ (7). From Table 2, it is shown that all brands were within the allowed friability limit.

\section{Content Uniformity Test}

Contents of carbamazepine tablets should be not less than $92.0 \%$ and not more than $108.0 \%$ of the labeled amount of active drug. Content uniformity test results (in Table 2) show that all conventional CBZ tablets fit this criterion.

\section{Dissolution Studies}

Oral bioavailability of CBZ is fully dependent on dissolution of product. It has been reported that the exchange of one marketed brand for another caused seizures and the occurrence of side effects (9). Therefore, the evaluation of dissolution data and comparison of dissolution profiles for different marketed brands are important. CBZ, a BCS Class II drug, is practically insoluble in water, and dissolution of this type of drug is generally done in the presence of surfactant. Figure 1 shows the percentage of drug released from the tablets. Difference $\left(f_{1}\right)$ and similarity $\left(f_{2}\right)$ tests were applied to the dissolution

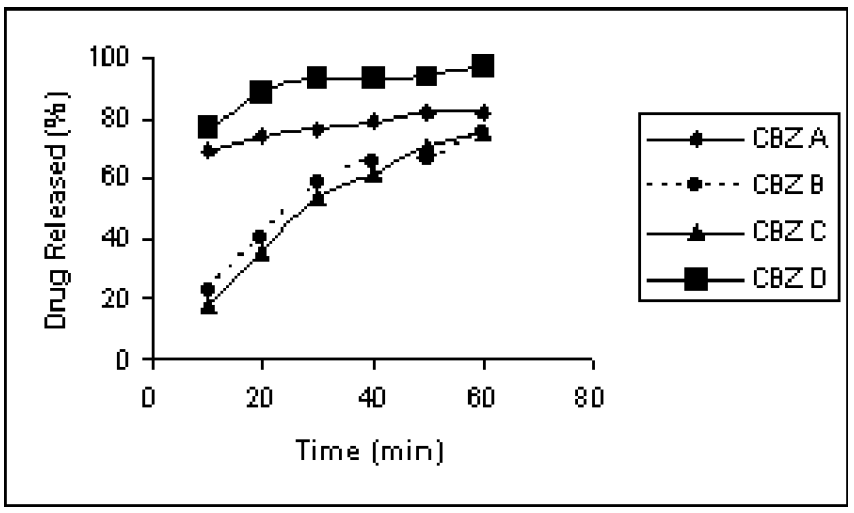

Figure 1.Dissolution profiles of conventional carbamazepine tablets. data and are listed in Table 3. These factors were used to compare the dissolution profiles of different brands of conventional carbamazepine tablets. In the first instance, the dissolution data for different marketed products were evaluated for compliance with USP dissolution specifications. According to the USP (6), drug dissolved for all conventional CBZ tablets should be at least $75 \%$ of the labeled amount. All met the USP specification (i.e., released $75 \%$ of labeled amount within $60 \mathrm{~min})$. CBZ D released the maximum amount of drug $(97.31 \%)$, and CBZ B showed the lowest drug release (75.4\%).

CBZ D was then considered the reference for maximum drug release. Dissolution profiles of other marketed products ( $C B Z A, C B Z B$, and CBZ C) were compared against the reference (CBZ D). The $f_{1}$ and $f_{2}$ values indicate that the dissolution profiles of CBZ A are similar to the profile of reference (CBZ D). However, the release profiles of $C B Z B$ and $C B Z C$ are not similar to the release profile of CBZ D (reference).

\section{CONCLUSION}

The present investigation demonstrates that carbamazepine tablets manufactured by different Indian manufacturers show acceptable results for all physicochemical tests. Because carbamazepine is a BCS Class II compound (low solubility, high permeability), dissolution can play a significant role in the oral absorption of this drug. There are differences in the dissolution profiles of marketed brands, and therefore, an in vivo study is needed to further investigate the bioavailability of marketed carbamazepine formulations.

\section{ACKNOWLEDGMENT}

The authors are grateful to Sun Pharma, Dadra, for providing carbamazepine. We greatly acknowledge Mr. Aniruddha Chandra for his fullest support throughout the study.

Table 3. Difference $\left(f_{1}\right)$ and Similarity $\left(f_{2}\right)$ Factors for Reference (CBZ D) versus Test Products (CBZ A, B, and C)

\begin{tabular}{lccc}
\hline Factors & CBZ A & CBZ B & CBZ C \\
\hline$f_{1}$ & 15 & 39 & 42 \\
\hline$f_{2}$ & $\underline{88}$ & 49 & 45 \\
\hline
\end{tabular}




\section{REFERENCES}

1. McNamara, J. O. Drugs Effective in the Therapy of the Epilepsies. In Goodman \& Gilman's The Pharmacological Basis of Therapeutics, 10th ed.; Hardman, J. G., Limbird, L. E., Eds.; McGraw-Hill: New York, 2001; pp 533-534.

2. Konsil, J.; Dechasathian, S.; Mason, D. H.; Stevens, R. E. Reanalysis of carbamazepine and carbamazepineepoxide pharmacokinetics after multiple dosing of extended release formulation. J. Pharm. Pharm. Sci. 2002, 5 (2), 169-175.

3. Çomoğlu, T.; Gönül, N. Quality Control Studies on Conventional Carbamazepine Tablets Available on the Turkish Drug Market. Turk. J. Med. Sci. 2005, 35 (4), 217-221.

4. Banker, G. S.; Anderson, N. R. Tablets. In The Theory and Practice of Industrial Pharmacy, 3rd ed.; Lachman, L., Lieberman, H. A., Kanig, J. L., Eds.; Varghese Publication House: Bombay, India, 1990; pp 300-301.
5. Lachman, L.; Lieberman, H. A.; Kanig, J. L. The Theory and Practice of Industrial Pharmacy, 3rd ed.; Varghese Publication House: Bombay, India, 1990; pp 296.

6. The United States Pharmacopeia and National Formulary USP 28-NF 23; The United States Pharmacopeial Convention, Inc.: Rockville, MD, 2005; pp 341-344, 2411-2420, 2501-2510, 2670.

7. Moore, J.W.; Flanner, H. H. Mathematical comparison of dissolution profiles. Pharm. Tech. 1996, 20 (6), 64-70.

8. Parrot, E. L.; Saski, W. Solid Pharmaceuticals. In Experimental Pharmaceutical Technology, 3rd ed.; Burgess Publishing Co.: Minneapolis, MN, 1971; pp 58-106.

9. Olling, M.; Mensinga, T.T.; Barends, D. M.; Groen, C.; Lake, O. A.; Meulenbelt, J. Bioavailability of carbamazepine from four different products and the occurrence of side effects. Biopharm. Drug Dispos. 1999, 20 (1), 19-28. 